\title{
Inhaled budesonide plus oral prednisone reduced relapse after discharge from the emergency department for acute asthma
}

\author{
Rowe BH, Bota GW,Fabris $L$, et al. Inhaled budesonide in addition to oral corticosteroids to prevent asthma relapse \\ following discharge from the emergency department. A randomized controlled trial.JAMA 1999 Jun 9;281:2119-26.
}

QUESTION: In patients discharged from the emergency department (ED) with acute asthma, does the addition of inhaled budesonide to a fixed dose of oral prednisone reduce relapses?

\section{Design}

Randomised (allocation concealed*), blinded (patients and outcome assessors),* placebo-controlled trial with 21-day follow-up.

\section{Setting}

A community hospital ED in Sudbury, Ontario, Canada.

\section{Patients}

191 patients $16-60$ years of age who were treated in the ED for acute asthma and had a peak expiratory flow rate $<80 \%$ predicted for sex, age, and height. Patients were excluded if they had received oral or inhaled corticosteroids during the previous week. Follow-up was $94 \%$.

\section{Intervention}

All patients were given a non-tapering, 7-day course of oral prednisone, $50 \mathrm{mg} /$ day, at discharge. 94 patients were allocated to an inhaled budesonide Turbuhaler (2 inhalations of $400 \mu \mathrm{g}$ each twice daily for a total of $1600 \mu \mathrm{g} / \mathrm{d}$ ) for 3 weeks, and 94 were allocated to placebo Turbuhaler.

\section{Main outcome measures}

Self-reported relapse (unscheduled visit for worsening of asthma symptoms) validated by computerised hospital records. Secondary outcomes included quality of life (Asthma Quality of Life Questionnaire), self-reported asthma symptoms, and $\beta$-agonist inhalations in previous 24 hours.

\section{Main results}

188 patients (mean age 28 y, $61 \%$ women) were included in the intention-to-treat analysis. At 21 days, patients who received budesonide had fewer relapses $(p=0.049)$ (table); had higher quality-of-life scores (5.9 $v 5.2$, $\mathrm{p}=0.001$ ); had fewer symptoms of cough (5.6 $v 4.7$, $\mathrm{p}=0.004)$, breathlessness $(5.8 v 4.9, \mathrm{p}=0.001)$, wheezing (5.9 $v 5.0, \mathrm{p}=0.001)$, and night-time wakening (6.2 v 5.4, $\mathrm{p}=0.001)$; and used fewer $\beta$-agonist inhalations in the previous 24 hours $(2.4 v 4.2, \mathrm{p}=0.01)$ than patients who received placebo.

\section{Conclusion}

In patients with acute asthma who were discharged from the emergency department, the addition of inhaled budesonide to a fixed course of oral prednisone reduced relapses, symptoms, and use of inhaled $\beta$-agonists and improved quality of life.

*See glossary.

\section{COMMENTARY}

This well-designed, well-executed study by Rowe and colleagues had a high level of follow-up over 21 days. It showed clinically important reductions in relapse and symptoms, as well as increased quality of life, resulting from the addition of inhaled corticosteroids to oral corticosteroids for patients who were discharged from the ED after an episode of acute asthma. The number needed to treat ( 9 patients to prevent 1 additional relapse) suggests that this combination therapy is sensible for adults with uncomplicated asthma, but replication studies of combination therapy with inhaled preventer medication are needed to assess the effects in other patient groups, such as children.

Rowe and colleagues cite current consensus guidelines that do not make firm recommendations for the use of inhaled corticosteroids in the ED; such guidelines should now incorporate this new evidence. Many of the $63 \%$ of patients who presented with asthma to the ED and were not already receiving inhaled corticosteroids could probably have benefited from use of this treatment.

It is also uncertain to what extent the clinical evaluation in the ED considered such asthma precipitants as smoking and allergies to indoor pets. Such clinical evaluation remains important, as does education and regular review of patients, all of which should result in reduced admission to hospital and ED attendance. ${ }^{1}$ Future research is needed to identify patients who do not need oral corticosteroids in addition to inhaled corticosteroids and those who would benefit from continued inhaled corticosteroids beyond 21 days after ED discharge.

Louis S Pilotto, MBBS, PhD North West Adelaide Health Service Brian J Smith, MBBS, PhD University of Adelaide Woodville, South Australia, Australia

1 Gibson PG, Coughlan J, Wilson AJ, et al. Self management education and regular practitioner review for adults with asthma. Cochrane Review, latest version 29 May 1998. In: Cochrane Library. Oxford: Update Software.

Inhaled budesomide v placebo for acute asthma at 21 days after discharge from the emergency department ${ }^{\dagger}$

\begin{tabular}{ccccc} 
Outcome & Budesonide & Placebo & RRR (95\% CI) & NNT (CI) \\
Relapse & $13 \%$ & $25 \%$ & $48 \%(3$ to 72$)$ & 9 (5 to 179$)$ \\
\hline
\end{tabular}

†Abbreviations defined in glossary; RRR, NNT, and Cl calculated from data in article. 